\title{
Socio-economic evaluations of nature protected areas: health first effect
}

\author{
Sanja TISMA ${ }^{1^{*}}$, Ana-Maria BOROMISA ${ }^{1}$ \\ Anamarija FARKAS ${ }^{1}$, Iva TOLIC ${ }^{1}$
}

\author{
${ }^{1}$ Institute for Development \& \\ International Relations - IRMO, Croatia
}

\section{Keywords:}

nature park, forest

ecosystem,

health and

recreational

function,

innouative tools for

payment for

ecosystem services

\begin{abstract}
The importance of protected areas rich in forest ecosystems rapidly grows. Forests in parks become recreation centres for cities near protected areas having strong health function. Thus, also Meduednica Nature Park near Zagreb, the capital of Croatia, is frequently used as lungs of the city. The research presented in this article aims to valorise the health function of the Forest Ecosystem Service (FES) in the Nature Park and develop the Payment for Ecosystem Services (PES) methodology to be used for the assessment of the introduction of the entrance fee payment for the Park. The article provides a methodological framework for validation of health function of the forest ecosystem of the Meduednica Nature Park. It also brings a socio-economic assessment of the health function of the forests in the Park. The measurement results and assessments emphasize the need to raise public awareness of health benefits of FES and FES in general.
\end{abstract}

The publication of the European Journal of Geography (EJG) is based on the European Association of Geographers' goal to make European Geography a worldwide reference and standard. Thus, the scope of the EJG is to publish original and innovative papers that will substantially improve, in a theoretical, conceptual or empirical way the quality of research, learning, teaching and applying geography, as well as in promoting the significance of geography as a discipline. Submissions are encouraged to have a European dimension. The European Journal of Geography is a peer-reviewed open access journal and is published quarterly. 


\section{INTRODUCTION}

Since the second half of the last century nature and nature protected areas have experienced a profound mutation through which both their position and role in social dynamics have been transformed. Today, nature protection areas have strong impact on society in terms of sustainable human development, economic, environmental, social and health functions. In this matter, nature protected areas with significant forest areas are of particular importance to big urban centres. These areas become important meeting places for recreation thus contributing to physical and mental health of people. Forests and urban green areas in the most urbanised countries with the highest population in Europe are usually also main sources of landscapes with public access. Forest recreation with its diversity of values and benefits contributes to both psychological and physical health of the residents of the nearby cities.

Although in the past forests were mainly evaluated as source of timber, today general benefits of forests functions gain increasing significance. Besides ecological functions of forests such as preservation of biodiversity, air quality, counter erosion functions, climate functions are increasingly valued. Also, other functions directed towards wellbeing and general improvement of psychological and physical state of the people living in the close vicinity of forests who visit them and enjoy the characteristics of open forest spaces. Nowadays, secondary forest products such as mushrooms and other forest fruit become more significant (Fürst, Luque and Geneletti, 2017).

The latest "EU Forest Strategy: for forests and the forest-based sector", that the European Commission introduced in September 2013 (European Commission, 2013), has brought a new approach to forest protection and conservation of biodiversity improving sustainability of both the use as well as delivery of services of forest ecosystem. Coherent and holistic approaches are promoted in forest management covering: $i$ ) multiple benefits and services of forest; ii) internal and external forest-policy issues and $\mathrm{iii}$ ) the complete forest value-chain. So, the strategy promotes an integrated view of forest ecosystems stressing the importance of their mapping in struggle against challenges they are facing (Maes, Teller and Erhard, 2014).

Nature Park (NP) Meduednica is located near Zagreb, the capital of Croatia, with an area of 17,938 ha. $78 \%$ of the area are forests, $50 \%$ of which are state owned, $47 \%$ are private ownership while $3 \%$ are owned by the Faculty of Forestry, University of Zagreb. The whole area is a Natura 2000 site. In the area of the Meduednica Park there are 70 mountain trails, 8 bike trails, 1 enduro bike trail, 1 cave (geomorphological monument of nature), 1 mine (for tourist visiting), Meduedgrad - medieval fortress (cultural heritage of the Republic of (roatia), about 10 mountain huts, a hotel, ski slopes, etc. Meduednica is increasingly becoming a sports-recreational and tourist destination. Rich forest ecosystem is particularly important during summer when the population in the surrounding area seek refreshment on the mountain.

The main function of the nature park is to protect the natural area from a greater concentration of economic activities or over-construction. As opposed to national parks, it is important that there had been certain forms of economic activity and residential construction in the area of the nature park even before it was proclaimed. Therefore, tourism or other economic activities do not necessarily exclude themselves from the area of the nature park. However, they should be reduced to boxes that will not destroy the main phenomenon that triggered the protection in the first place (e.g., conflict of expansion of ski resorts and forest area in the Meduednica Nature Park). 
The total number of visitors to all national parks in the Republic of Croatia in 2010 was approximately 2.1 million (Croatian Bureau of Statistics, 2011), while in 2018 the number of visitors was approximately 3.9 million. These data result from a global trend of increasing interest in visiting protected areas, better and more efficient promotion of parks, increase in the number of travel agencies offering specialized programs or organized visits to protected areas as well as from raising awareness of the benefits of staying in nature and recreational activities.

The Nature Park Meduednica is popular for hiking, climbing, cycling and its winter sports centre (with four kilometres of ski slopes). In 2015, almost 30,000 people visited the Park and participated in several programs and events. The biggest tourist attractions in the Park are the Veternica Cave, the Zrinski Mine and the Meduedgrad Castle. In 2013, nine new $150 \mathrm{~km}$ long bike lanes were opened. During the summer months, the Park also offers relief from heat waves. Zagreb is usually $1.5^{\circ} \mathrm{C}$ warmer than the surrounding areas due to the impact of urban heat. Traditional events and happenings are the Fantastic Zagreb Film Festival at Meduedgrad, International Music Nights, European Bat Night, Medieval Days on the mountain of Meduednica, Fairy tale Summer on the Medvednica mountain.

\section{PREVIOUS RESEARCH}

Health functions, as one of the many services of forest systems, are the subject of many scientific researches and papers. For example, Hartig, et al. (2010) consider how experiences of nature can affect human health and well-being. They state that surveys in numerous countries show that many people visit natural areas in order to relax and ease feelings of tension. They also provide the overview of some of these most widely used theories and related empirical research.

Frumkin at al. (2007) propose that a research agenda about contact with nature and health, which identify main research domains and crucial questions whose answers could provide the foundation for interventions in the field of public health based on evidence. They identify research questions in seven domains: mechanistic biomedical studies; exposure science; epidemiology of health benefits; diversity and equity considerations; technological nature; economic and policy studies; and implementation science. Their conclusion is that the findings of the research can be guidelines to interventions throughout various "settings, populations, spatial scales, and forms of nature." Thus, a wide range of experts and professionals in the fields of health, ecology, landscape architecture, parks management, education, etc. will be able to apply these findings in order "to improve health and well-being on a large scale."

A study (using the generalised database) proves that those living in the greenest parts have lower adjusted mortality from cardiouascular diseases. The authors suggest that this is most likely due to greater physical activity (Mytton, Townsend, Rutter and Foster, 2012).

Another study analysing casual links between forests and human health has been carried out by Pierce Colfer, Sheil and Kishi (2006). Their research shows that the loss of forests negatively affects the human health. 
It is well known that experiencing nature have some positive mental effect. Moderately intensive physical activity, such as recreational walking and cycling also has substantial positive health effects. Nearby forests may help to promote such activities (Bell, 2007).

Pierce Colfer, et al. (2006) in the afore mentioned study of the link between forests and people's health have reached the similar conclusion i.e. there is significant evidence that, in many cases, activities promoting economic development, such as construction of dams, roads and mines as well as activities leading to deforestation, have worsened the health of those living near forests.

Forest bathing is the new term meaning going out into the woods to enhance physical and mental health of humans. In their research, Mao, Lan and Yan (2012), aimed at investigating the effects the short-term forest bathing has on human health. Twenty subjects participated in the study. They were separated in two groups. One group was sent on a two-night trip to a broad-leaved evergreen forest, and the other was sent to a city area. Subjects exposed to the forest environment showed reduced oxidative stress and pro-inflammatory level. Thus, they concluded that forest bathing was beneficial to human health, perhaps through preventive effects related to several pathological factors.

According to Dwyer, Nowak and Noble (2003), the urban forests have a special significance for the improvement of living conditions of the residents in urban areas. They support the opinion that sustainability is very important for forest management in urban areas and conclude that new information should be the basis of urban management activities.

Similar results were obtained in a field survey by Hansmann, Hug and Seeland (2007), who analysed the effects of the forest in the city park in Zurich, Switzerland. The results of the research have shown that one of the key motives to visit the forest park was the decrease of stress and a growing feeling of wellbeing. Comparing the visitors' feelings before and after the stay in the forest proved that the stress level has been significantly reduced as well as the feelings of restlessness and dissatisfaction while the feeling of physical wellbeing has increased. The decrease of headaches and decrease of anxiety were particularly emphasised as positive consequence. Additional mood change for better has been emphasised by the visitors who practiced some sport activities in the forest.

Rapid growth in cities across the globe has led to more than half of the world's population living in cities, with a worldwide urban growth rate of $2 \%$ from 2005 to 2010 (Dean, van Dooren and Weinstein, 2011). Biodiversity, or biological diversity is "the variability among living organisms from all sources including, inter alia, terrestrial, marine and other aquatic ecosystems and the ecological complexes of which they form part; this includes diversity within species, between species and of ecosystems." Biodiversity in cities is associated with improved mental health and wellbeing. Important quality that is unique to green spaces is that the contact with them provides recovery from stress and mental fatigue (uan den Berg, Maas, Verheij and Groenewegen, 2010).

Several years later, Song et al. (2013) analyse physiological and psychological effects of walking on young males in urban parks in winter. Thirteen subjects were instructed to walk predetermined 15-minute courses in an urban park and in the city area. The results of three questionnaires indicated that walking in the urban forest park 
improved mood and decreased negative feelings and anxiety. This research also points out to the positive impact on human health due to their stay as well as moving within forest ecosystems even in the winter conditions, thus proving the thesis that recreational function forests has benefits for human health wellbeing.

Romagosa, Eagles and Lemieux (2015) conducted another research with the aim to clarify the links between time spent in the protected nature areas and their health and wellbeing. The research results once again show a linear linkage between stay in the forest, practicing forest recreational function and its beneficial feeling for body and spirit. Apart from the mentioned, this research points out to the growth of awareness and experience of the population on positive effects the forest and nature in general have on the human health. There is a growing number of benefits recognized by nature protected areas visitors resulting from enjoying ecosystem services and generally beneficial functions of the forests.

Research carried out by Maller, et al. (2009) and by Karjalainen, Sarjala and Raitio (2010) supplement the mentioned research claiming that if the change of unsustainable policies and lifestyles were put on hold until acquiring complete knowledge on the matter, the risk is to endanger both biosphere and health of people beyond repair. Also, it should be noted that forests are rich sources of natural medicinal plants.

Sandifer, Sutton-Grier and Ward (2015) paid special attention to the link between forest and protected nature areas visitors, health and biodiversity as one of the generally beneficial functions of forests. They pointed out to a strong interaction of biodiversity and production of ecosystem services as well as of exposure to nature and human health. The authors stressed the problem of allergies and respiratory diseases that could be reduced by the microbial diversity of forests. Before them there were not many studies devoted to that issue. Therefore, they are of the opinion that the planning of land use should be revised by development strategists, space planners and other decision makers by putting the wellbeing of humanity in the centre. This should be done by joint research of health scientists, ecologists, social scientists and planners on the development of new policies, which would boost interaction of humans with biodiversity and nature. In any case, the conclusion made is that biodiversity preservation whether as green forest islands or as nature protected areas is of crucial importance for human health and enhancing the quality of life within their immediate enuironment

According to Sanesi, Gallis and Kasperidus (2010) social research is important in forestry. It advocates social inclusion, cultural integration and wellbeing as core goals in modelling of a new European forest management.

One of the primary functions of forests is pollution reduction, which was subject of the research conducted by Nowak, et al. (2018). They analysed the air pollution removal by urban forests in Canada and found out that trees in 86 Canadian cities removed 16,500 tonnes of air pollution in 2010, with human health effects valued at 227.2 million Canadian dollars.

Moreover, forests have significant role in almost all of the Sustainable Development Goals (SDGs) of the United Nations 2030 Agenda (Katila, et al., 2019).

Lopoukhine, et al. (2012) claim that a wider range of actors should be included in a new agenda for protected nature areas that would devote increased attention to seascapes and landscapes under protection of "indigenous peoples, local communities, private owners and other actors complementing conservation areas managed by state 
agencies". They also emphasise that the green infrastructure should be included in the efforts of integration of main protected areas into sustainable development "as a strategic part of responses to climate change."

\section{METHODOLOGY}

The results of the research presented in this article are based on the desk research and data analysis further backed up with qualitative research methods. Desk analysis includes an in-depth review of the relevant scientific literature (books and articles) and auailable Internet sources. For the purpose of gathering the results of the relevant scientific research, scientific research platforms (e.g., Google Scholar, Science Direct, Social Science Premium Collection ProQuest, Springer Journals and Taylor and Francis) were extensively searched by key words such as nature park, health impact, innovative tools, bioeconomy.

Qualitative part of the research was conducted within the SINCERE - Innouating for Forest Ecosystem Services Project, co-funded under the call H2020-RUR-05-2017 of the Horizon 2020 research and innovation program in the period from 1 January 2018 to 31 December 2021. The qualitative research was conducted in a form of semi structured interviews survey in the second half of $\mathbf{2 0 1 8}$ with the aim to valorise the health function of the FES (Forest Ecosystem Service) in the Nature Park Meduednica. Additionally, the Payment for Ecosystem Services (PES) methodology was developed with the aim to foresee, simulate and predict the possibility to introduce the tickets payment approach in the Park. The survey was conducted among 155 visitors of different ages and backgrounds. The questionnaire consisted of 11 questions and was divided into two parts. The first part contained general questions, age, gender, education, while the second part concerned ecosystem services and their evaluation, as well as willingness to pay for forest ecosystem services, particularly recreational and health functions. The results were elaborated, presented and discussed within the stakeholder focus group in the end of 2019 in Zagreb.

\section{RESULTS}

Out of 155 visitors to the Meduednica Nature Park who completed the survey, 87 were men and 67 were women, while one person did not state the gender (Figure 1).

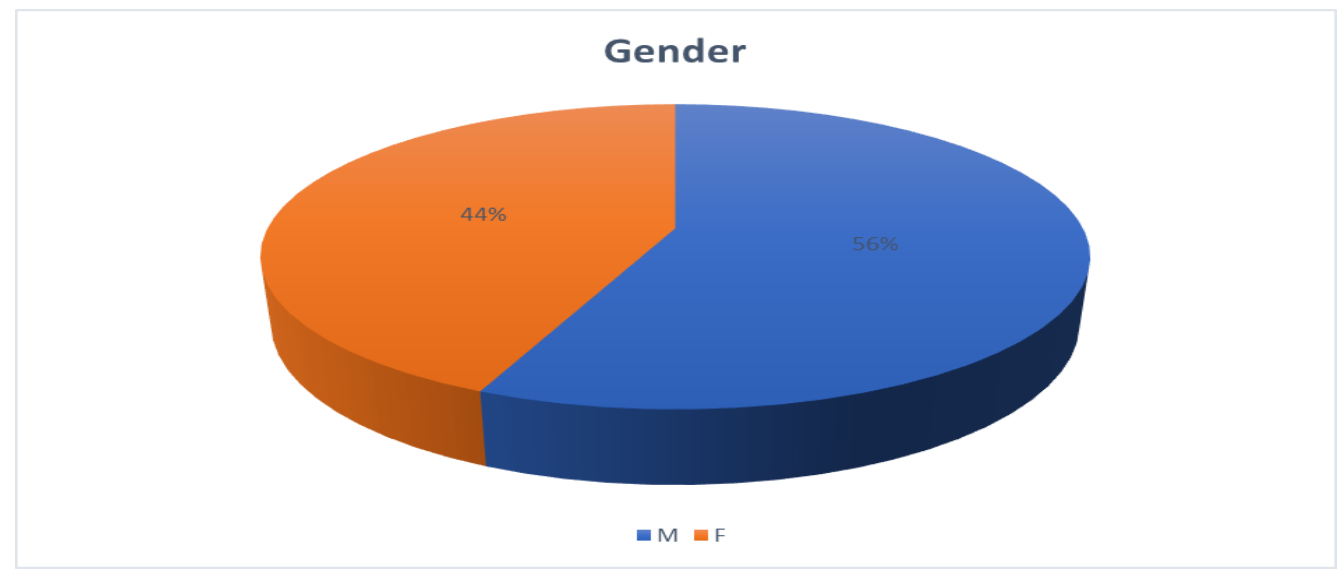

Figure 1. Gender of the participants \%. 
The majority of respondents, $68(43.87 \%)$, are in the age group of 31-45 years, followed by the age group of 18-30 (39 visitors or 25.16\%), 46-60 (30 visitors), 10 visitors are in the age group of 6-17 and 8 visitors are over 60 years of age (Figure 2).

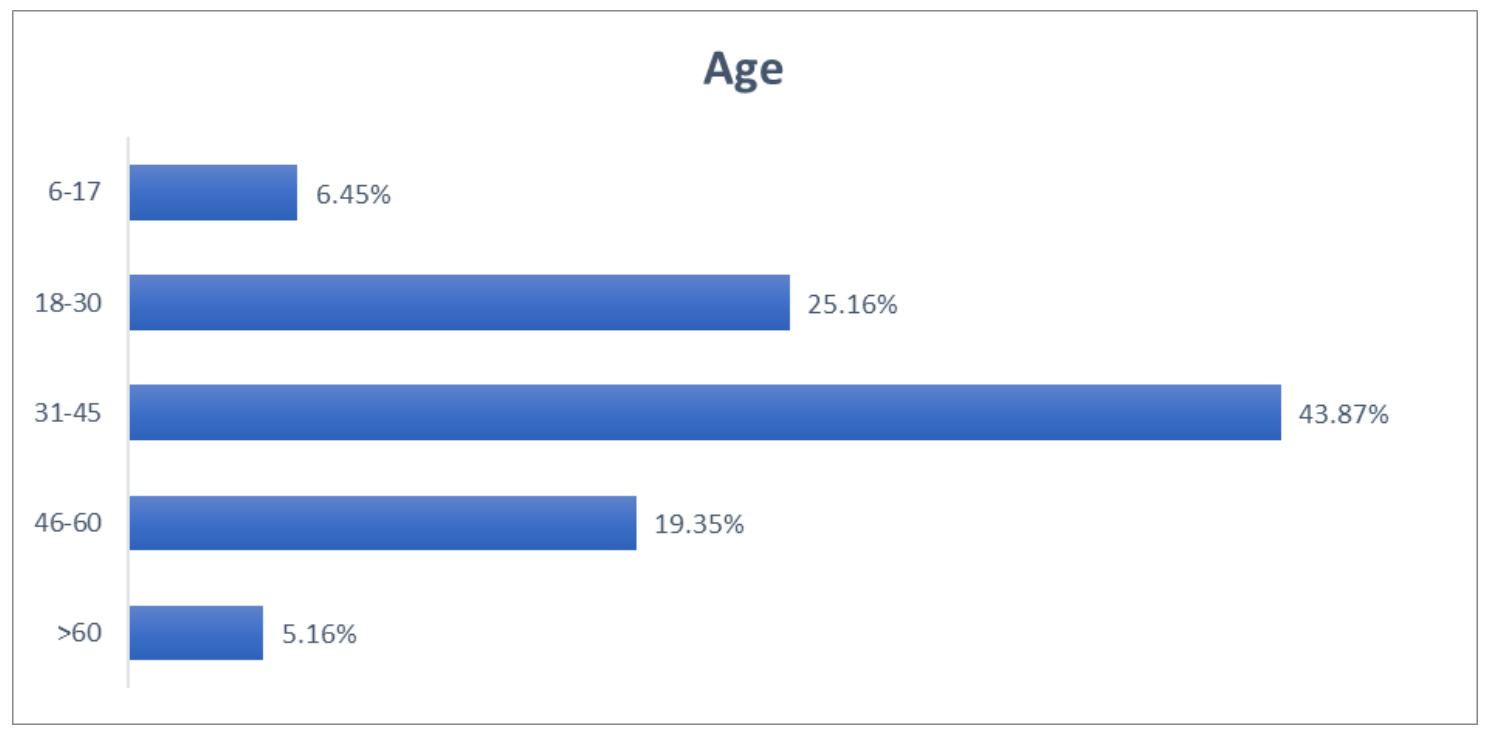

Figure 2. Age of the participants.

By level of education, the majority of visitors have a bachelor or master's degree - 85 of them, $(57.43 \%)$, followed by high school diploma holders - 49 visitors and 9 doctoral degree (PhD) holders (Figure 3 ).

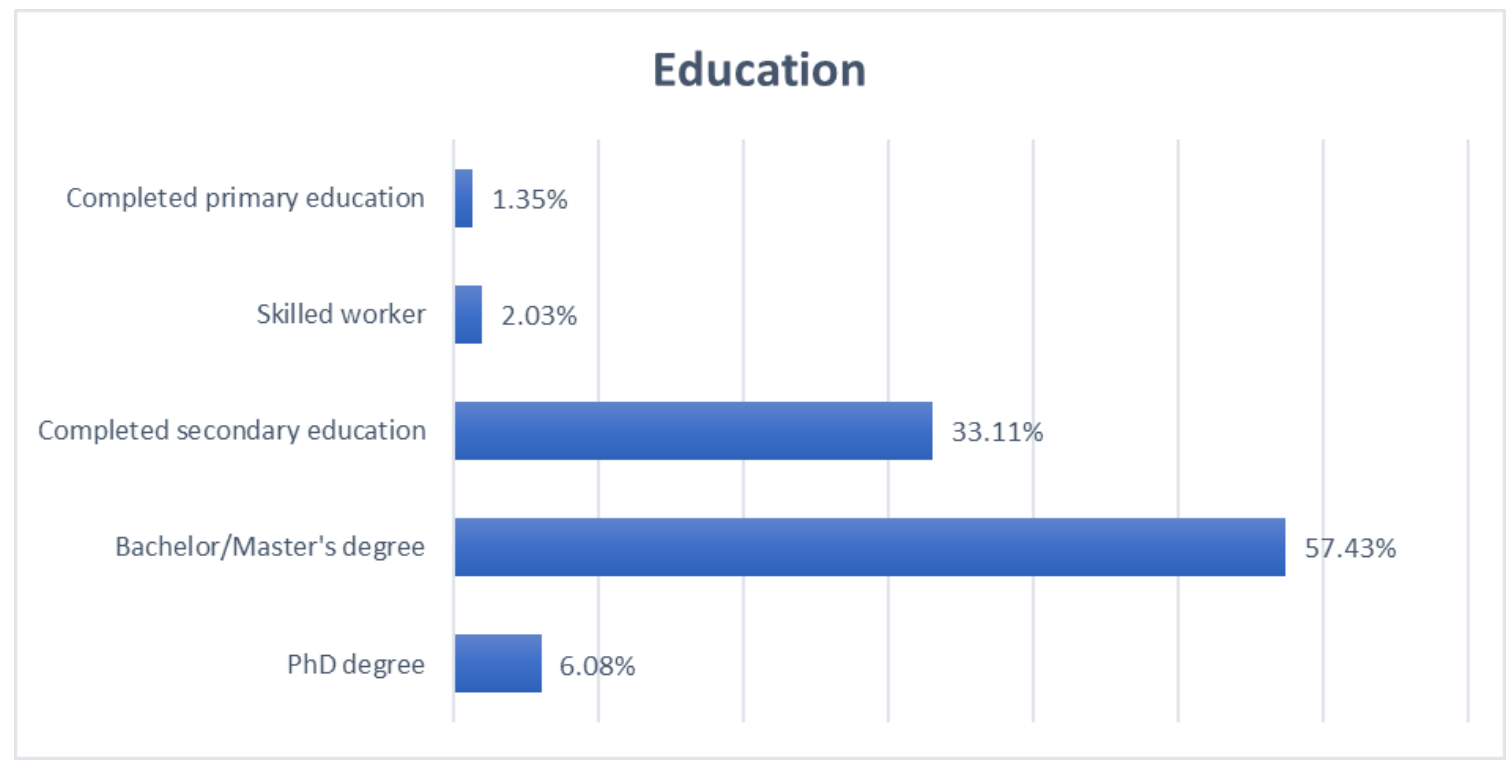

Figure 3. Level of education of the participants.

As expected, the highest number of visitors to the Medvednica Nature Park came from Zagreb. Out of 148 visitors who answered this question, 98 came from Zagreb $(66.2 \%)$. The visitors also come from other places, i.e. from Zaprešić (11 surveyed visitors), Velika Gorica and Samobor (5 visitors each), Zabok, Sesuete and Vinkouci (3 visitors each), Donja Stubica, Rijeka, Pula, Karlovac, Petrinja and Dugo Selo (2 visitors 
each) and from Sisak, Makarska, Jastrebarsko, Hruatsko Zagorje, Kerestinec, Austria, Switzerland and Russia (1 visitor each) (Figure 4).

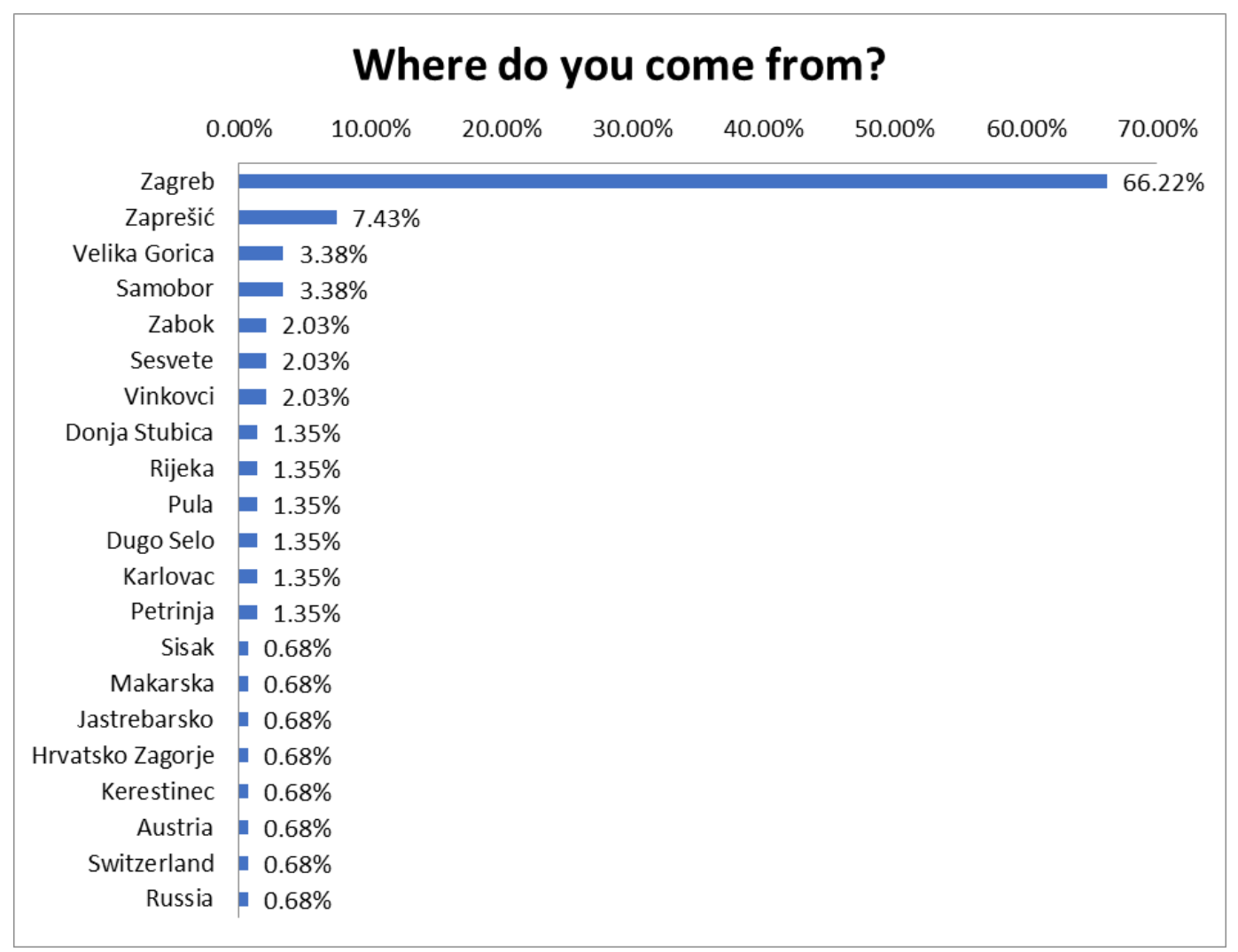

Figure 4. Location of the participants.

Most visitors do not know what forest ecosystem services are - 106 of them, while 48 visitors say they know (Figure 5). The most frequently named services of forest ecosystems are oxygen production (14 visitors), provision of natural recreational space (10 visitors), soil erosion protection and fresh air (7 visitors), water treatment, impact on psychophysical health and habitat of animals (5 visitors), providing a natural resting place, health services and air purification (4 visitors). Other forest ecosystem services mentioned are $\mathrm{CO}_{2}$ sequestration, biodiversity, climate change mitigation, tourism, balance management and many others (Figure 6).

Do you know what the forest ecosystem services are?

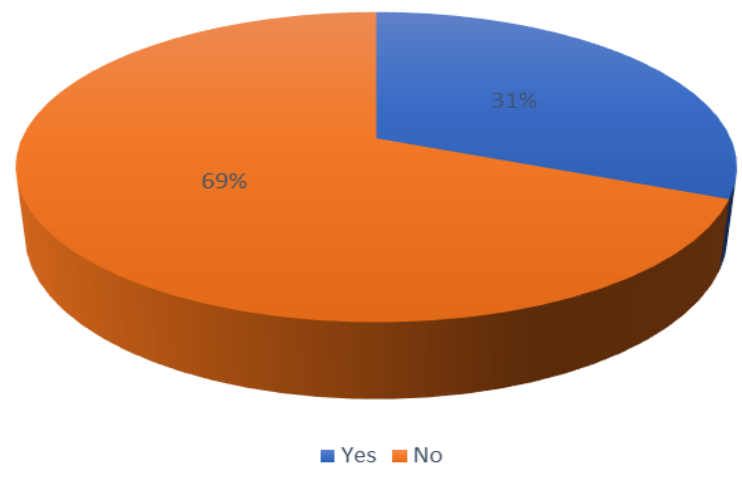

Figure 5. Knowledge of forest ecosystem services. 


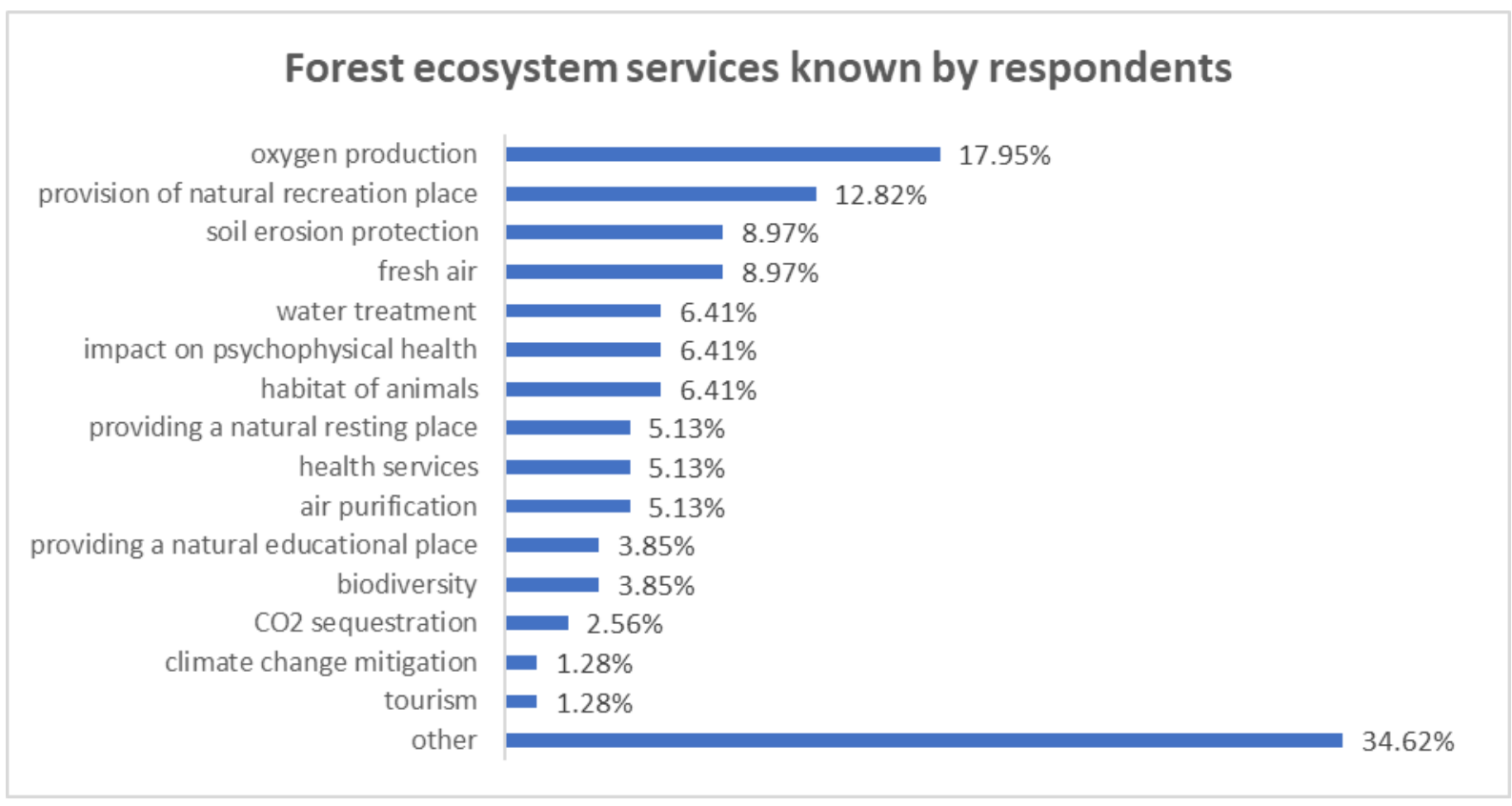

Figure 6. Forest ecosystem services the respondents know of.

When asked how often they visit Meduednica most of them, 59, answered 'several times a year'. $13.46 \%$ of respondents visit Meduednica once a year, $12.18 \%$ several times a week, $11.54 \%$ once a week, and the same percentage of participants visited Meduednica for the first time. Out of the surveyed visitors, $8.97 \%$ visit Meduednica several times a month while $4.49 \%$ visit it once a month (Figure 7 ).

The largest number of visitors, as many as 108, went up and down walking. Out of 47 visitors who responded that they did not climb walking, 18 of them walked for half an hour, 12 for one hour, 8 for two hours, three for three hours, while 6 did not answer the question (Figure 8).

\section{How often do you visit Medvednica?}

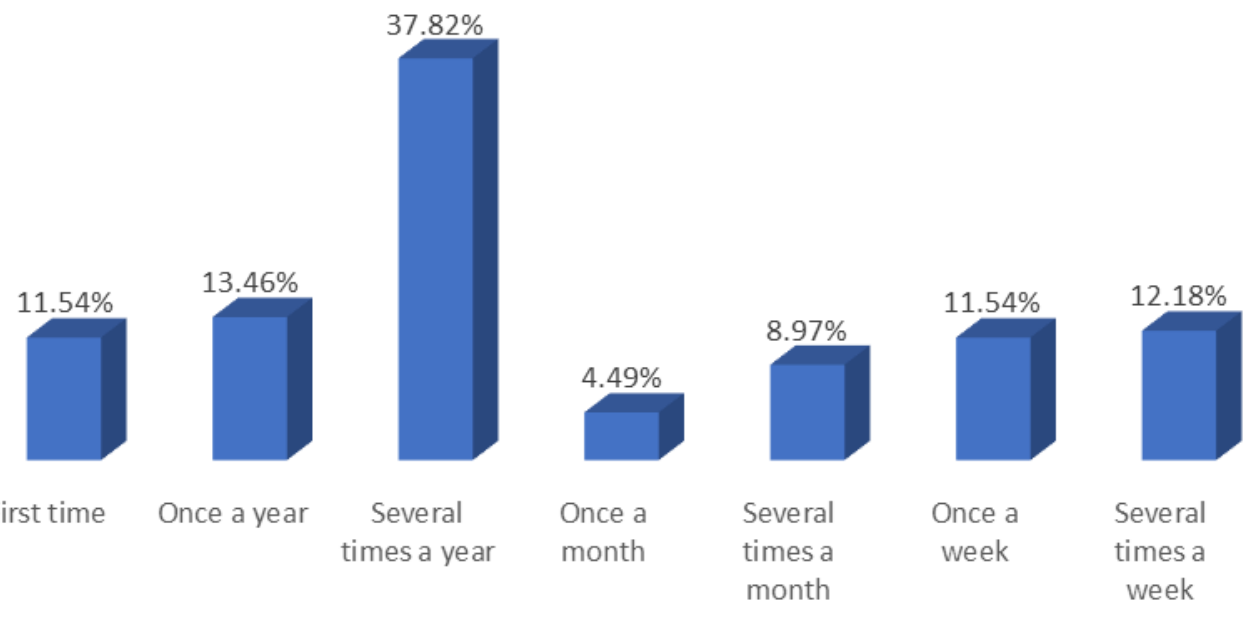

Figure 7. Frequency of visits to Meduednica. 


\section{Did you go up and down walking? If not, how long do you walk?}

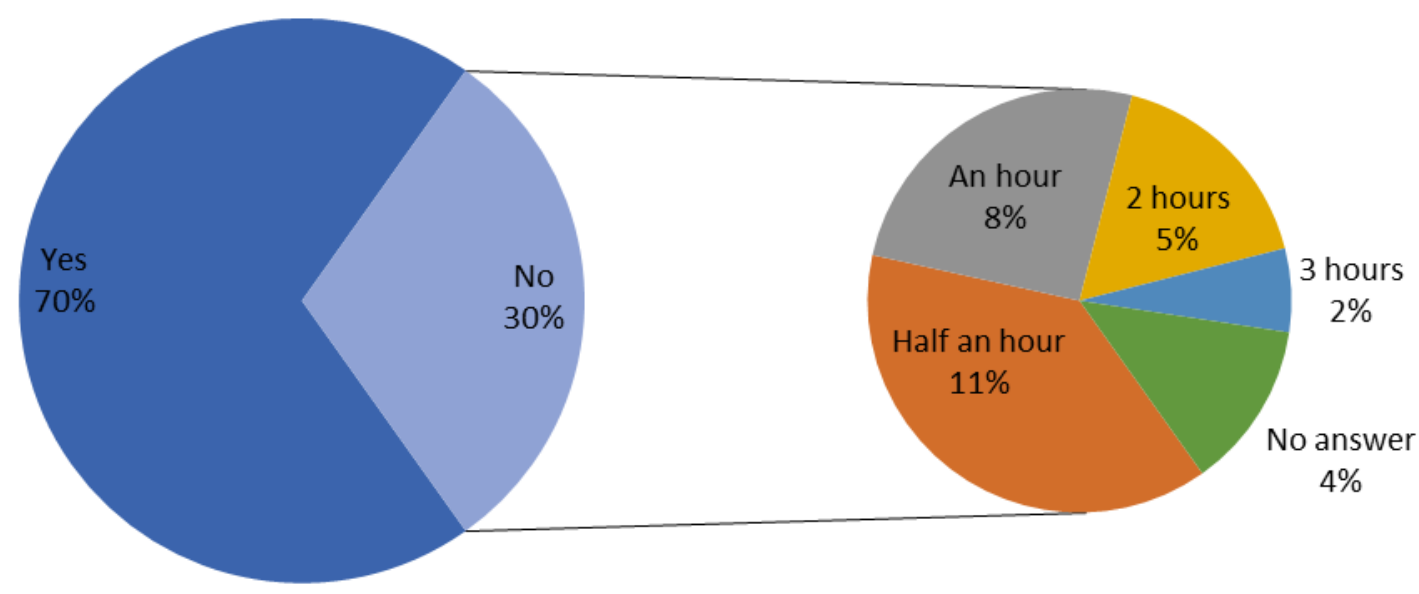

Figure 8. The length of walking.

When asked how often and how intensively they exercise, 26 respondents answered that they exercised 2-3 times a week, but they did not indicate intensity. Intensive activity is carried out 2-3 times a week by 20 subjects (12.35\%), while moderate activity is performed once a week and 2-3 times a week by 18 subjects $(11.11 \%)$. Out of the total number of subjects according to the intensity of other exercises, the majority of visitors practice moderate activity (30.25\%), while $16.67 \%$ practice the least intense activity. According to the frequency of exercise, most respondents exercise 2-3 times a week (44.44\%), and at least once a month (6.17\%) (Figure 9).

Claiming that a visit to the Meduednica Nature Park affects the improvement of social well-being (e.g. progress in some business activities, stronger connection/relationship with people, enjoyment of activities either alone or with others), $40.79 \%$ of visitors completely agree, $25.66 \%$ partially agree, $25 \%$ neither agree nor disagree, $6.58 \%$ partially disagree and $1.97 \%$ of the respondents completely disagree.

Also, the majority of respondents - $63.4 \%$ completely agree that staying in the Meduednica NP has the effect of improving psychological well-being (e.g., life satisfaction, improving mood, recovering from mental exhaustion, increasing motivation). $22.8 \%$ participants partially agree with this statement, $11.11 \%$ neither agree nor disagree, $1.96 \%$ partially disagree and $0.65 \%$ completely disagree.

According to $61.84 \%$ of participants, a visit to the Meduednica Nature Park fully affects the improvement of physical well-being (e.g., improvement of health status, maintenance of physical fitness), $23.03 \%$ of participants partially agree, $13.16 \%$ neither agree nor disagree, while $1.97 \%$ partially disagree. No one replied that they completely disagree with this claim (Figure 10).

The participants were also asked to compare the impact of the experience of visiting the Meduednica Nature Park on health and well-being with commercial products and services (Figure 11). Most of the respondents (33.33\%) compared this impact with a gym 
visit (HRK 35 per hour). 20.13\% compare it with a spa day (HRK 150 per day) and $15.72 \%$ compare it with going to the movies. The least number of visitors, $4.4 \%$, compare the visit to the Meduednica NP with a concert valued HRK 200.

\section{How often and how intensively do you exercise?}

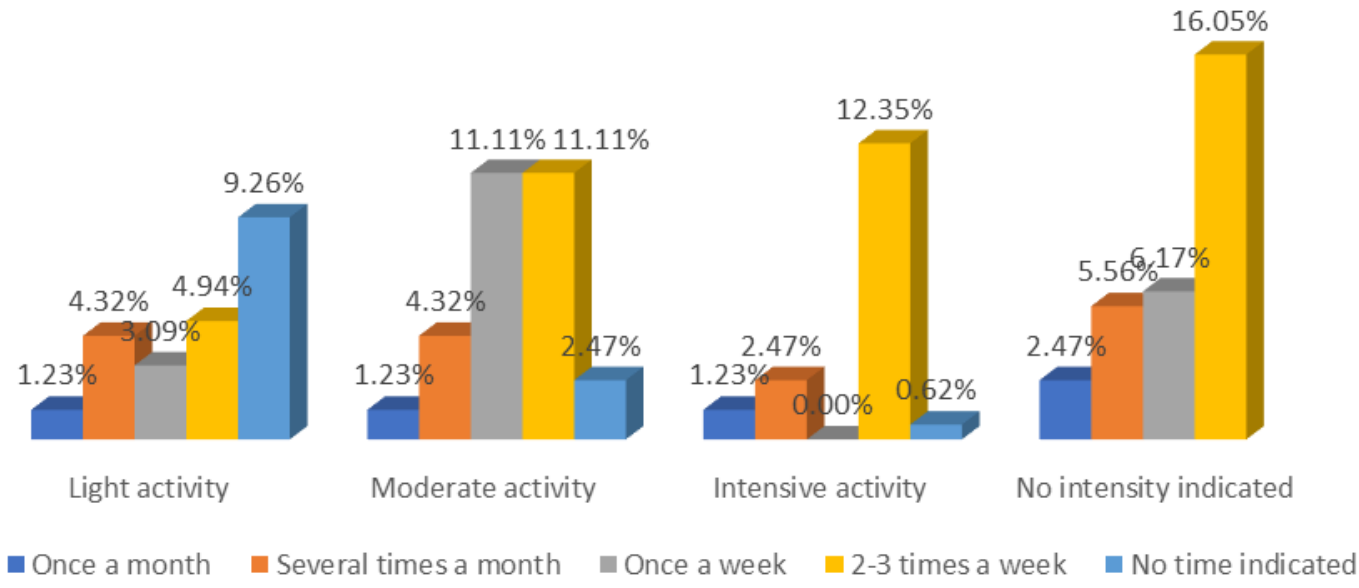

Figure 9. Frequency and intensity of exercise.

How much does the visit of Medvednica impact the following areas?

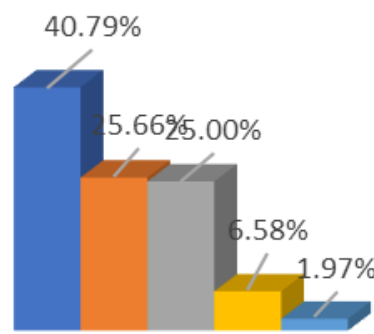

Improvement of social wellbeing

- Completely agree

- Partially disagree
$63.40 \%$

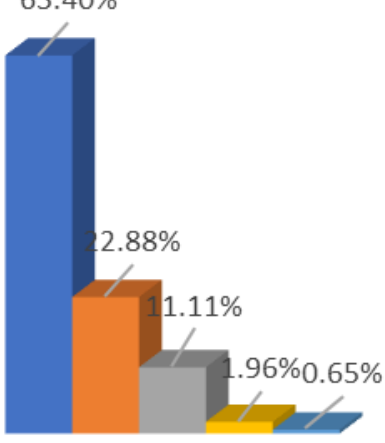

Improvement of psychological well-being

- Partially agreee

- Completely disagree

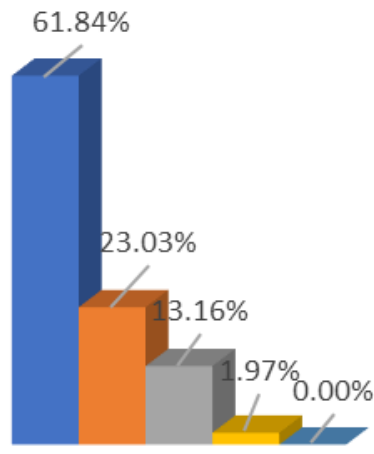

Improvement of physical well-being

Figure 10. The impact of the visits to Meduednica on social, psychological and physical well-being. 


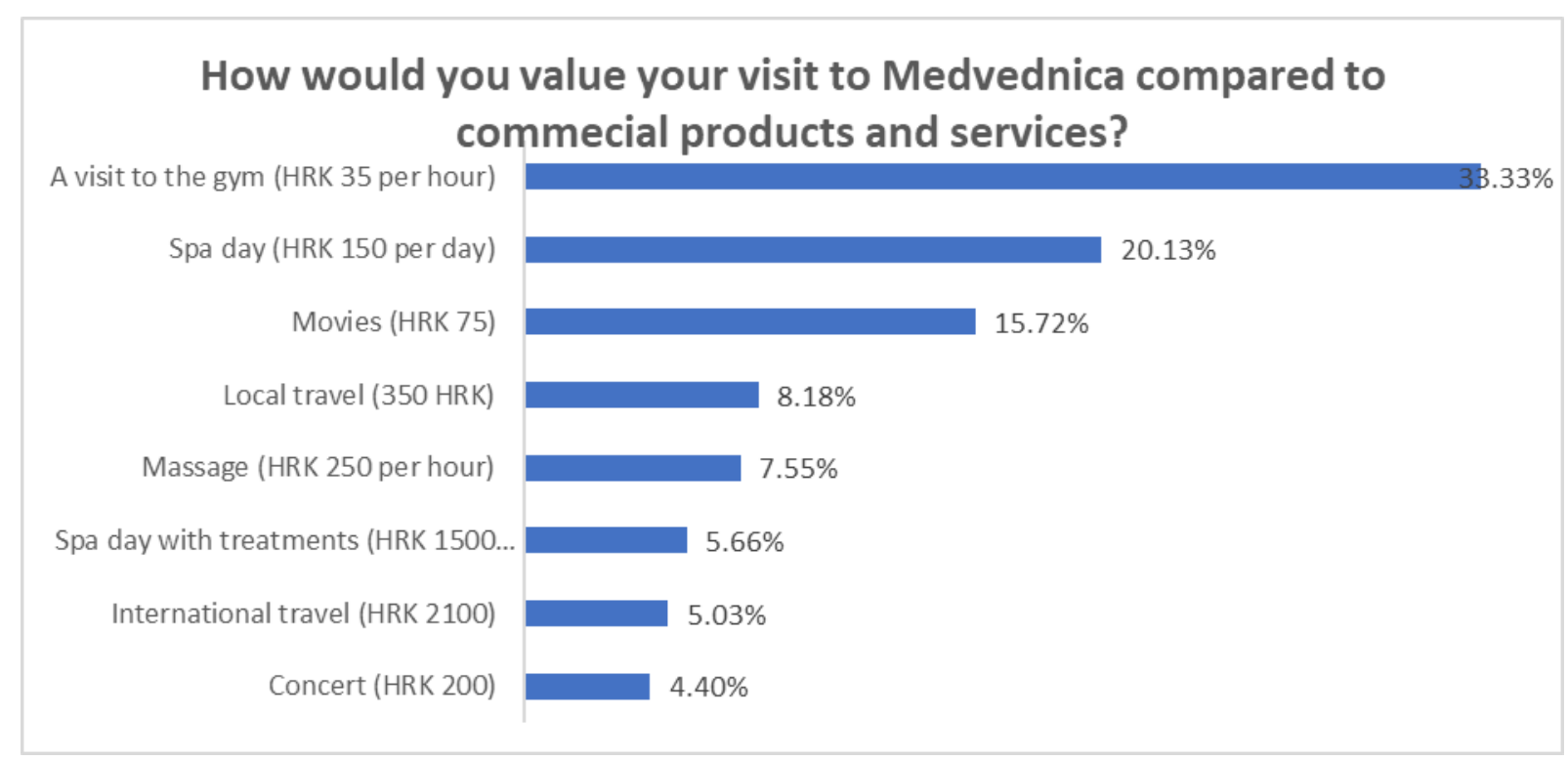

Figure 11. Visitation to Meduednica compared to commercial products and services.

Out of 102 visitors who answered the question whether they would be willing to pay for a visit to the Meduednica NP, 54 respondents (35.29\%) replied no, while $99(64.71 \%)$ replied yes. Out of the respondents who are willing to allocate money for staying in the Meduednica NP, $48.48 \%$ are willing to allocate HRK 10, $26.26 \%$ HRK 15 and $25.25 \%$ of the respondents are willing to allocate HRK 5 (Figure 12).

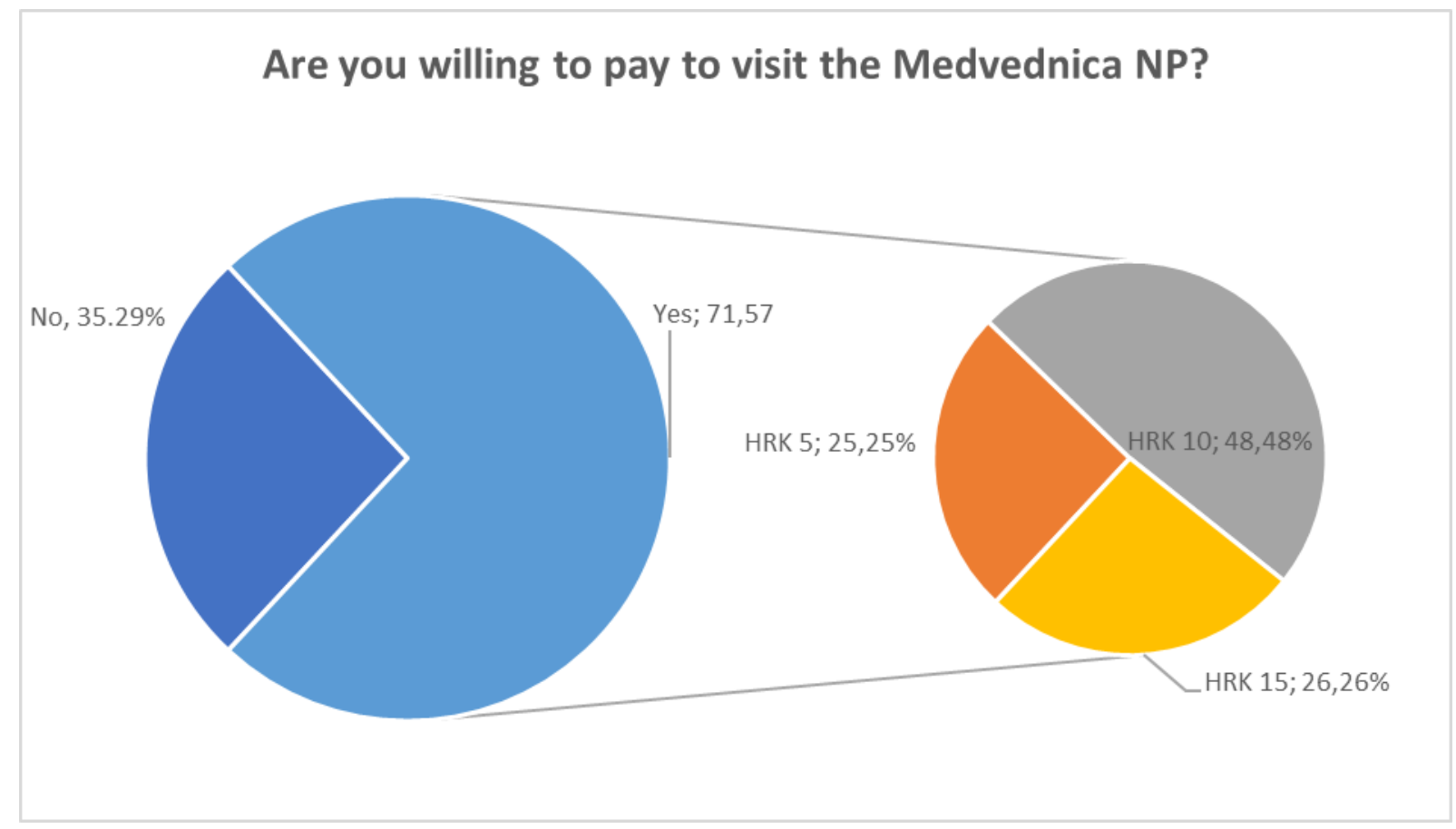

Figure 12. Willingness to pay the visit to the Meduednica NP.

\section{CONCLUSION}

Sustainable human development urges us to quantify some natural features that are intuitively significant, and thus to consider them when designing and using protected 
areas and their forest ecosystems. Along with direct benefits from the protection of forest ecosystems in protected areas (educational function, concession approvals for certain sports and recreational activities, fee for the permitted commercial and supporting services such as certification of local products, marketing services), there are significant indirect benefits for the local community, i.e. tax revenue, new jobs and revenues from the tourism services, transport and trade, sale of specific food products, etc.

However, there are some other functions of the ecosystem that are rarely assessed but has gained in significance during the last half of the century. Such key functions nowadays are recreational and health functions, which are intuitively felt, but rarely calculated, evaluated and charged. Therefore, this research aimed at investigation whether the population are familiar with and if they are how much they evaluate these functions of the forest ecosystem of the Nature Park Meduednica.

The starting points in the research were that a sustainable development respects the receiving capacity, i.e. the ability of the environment to withstand pollution and depletion of natural resources. In the case of protected areas, this takes on a new dimension. Since they are usually very attractive to visit and the tourist and recreational functions are their basic purposes, it is extremely important to implement it in such a way and to the extent that it will not impair the original natural and cultural qualities. The consequences of degradation due to unsustainable development are damage to human health, endangerment and disappearance of certain plant and animal species, air and water poisoning, degradation and soil erosion, etc.

Within such a framework, the Meduednica Nature Park is in a way a source of wellbeing for the urban area of the city of Zagreb as well as foe increasingly significant number of tourists visiting it throughout the year.

It is the most accessible large protected area for 1.2 million citizens of Zagreb. The Park, accessible by public transport, provides visitors with leisure, recreational, sports and education opportunities in a rich biodiversity environment.

The conducted research shows that most of the visitors of the Nature Park Meduednica do not know what forest ecosystem services are, but those who do recognize more services than just the primary ones, such as oxygen production and wood mass. They are aware that forests are much more than just wood and trees. Moreover, most of the participants believe that staying in nature improves their social, psychological and physical well-being.

However, even though visitation to Meduednica is mostly compared to the gym, i.e. work out, and a spa day, i.e. relaxation, less than half of the participants are willing to pay for the visitation to the Meduednica Nature Park.

One of the crucial problems causing such an attitude is lack of education on the values of the Park and its forest as well as on the health benefits provided by the enjoyment of these forest ecosystem functions. Also, one of the reasons is a lack of inclusion of the citizens into participative Park management, which is generally new in Nature based areas in Croatia. Via a focus group meeting, where the research findings were presented the citizens showed distrust and lack of knowledge about park management as well as about the planned works in the protected area and activities on preservation of forest surfaces. They pointed out the fact that if they knew how the financial sources obtained from the entrance tickets were spent, they would, in a 
substantially simpler way, allocate the money for the entrance tickets or for some other activities organized in the Park.

During the past several years sophisticated models of monitoring and eualuating of urban green networks and forest surfaces as well as their positive effects on population have been developed (Mougiakou and Photis, 2014)

\section{ACKNOWLEDGEMENT}

This article is the result of the research done under H2020 SINCERE, Innovating for Forest Ecosystem Services Project

\section{REFERENCES}

Bell, S. (2007). Forest recreation: new opportunities and challenges for forest managers. Radovi: izu. br. 10: 155-160.

Colfer, C. J. P., Sheil, D., Kaimowitz, D., and Kishi, M. (2006). Forests and human health in the tropics: some important connections. Unasylva: 57(224): 3-10.

Croatian Bureau of Statistics. (2011). Visitors to main tourist sigths and attractions. Available at: https://www.dzs.hr/

Dean, J., van Dooren, K., and Weinstein, P. (2011). Does biodiversity improve mental health in urban settings? Medical Hypotheses: 76(6): 877-880.

Dwyer, J., Nowak, D., and Noble, M. (2003). Sustaining urban forests. Journal of Arboriculture: 29(1): 49-55.

European Commission. (2013). Communication from the Commission to the European Parliament, the Council, the European Economic and Social Committee and the Committee of the Regions. A new EU Forest Strategy: for forests and the forest-based sector. Brussels: European Commission. Auailable at: http://eurlex.europa.eu/resource.html?uri=cellar:21b27c38-21fb-11e3-8d1c01aa75ed71a1.0022.01/DOC 1\&format=PDF Accessed: 23 March 2020

Frumkin, H., Bratman, G., Breslow, S., Cochran, B., Kahn Jr, P., Lawler, J., Levin, P., Tandon, P.S., Vaarnasi, U., Wolf, K. L. and Wood, S.A. (2007). Nature contact and human health: A research agenda. Environmental Health Perspectives: 125(7): 1-18.

Fürst, C., Luque, S., and Geneletti, D. (2017). Nexus thinking - how ecosystem services can contribute to enhancing the cross-scale and cross-sectoral coherence between land use, spatial planning and policy-making. International Journal of Biodiversity Science, Ecosystem Services and Management: 13(2): 412-421.

Hansmann, R., Hug, S. M., and Seeland, K. (2007). Restoration and stress relief through physical activities in forests and parks. Urban Forestry \& Urban Greening: 6(4): 213225.

Hartig, T., van den Berg, A., Hagerhall, C., Tomalak, M., Bauer, N., Hansmann, R., Ojala, A., Syngollitou, E., Carrus, G., van Herzele, A., Bell, S., Marie Therese Camilleri Podesta, M. T., and Waaseth, G. (2010). Health benefits of nature experience: psychological, social and cultural processes. In Forests, Trees and Human Health, eds. K. Nilsson, M. Sangster, C. Gallis, T. Hartig, S. de Vries, Seeland, K. and Schipperijn, J., 127-168. Dodrecht: Springer. 
Karjalainen, E., Sarjala, T., and Raitio, H. (2010). Promoting human health through forests: overview and major challenges. Environmental Health and Preventive Medicine: 15(1): 1-8.

Katila, P., Pierce Colfer, C., de Jong, W., Galloway, G., Pacheco, P., and Winkel, G. (2019). Sustainable development goals: their impacts on forests and people. Cambridge: Cambridge University Press.

Maes, J., Teller, A., and Erhard, M. (2014). Mapping and assessment of ecosystems and their services. Indicators for ecosystem assessments under action 5 of the EU biodiversity strategy to 2020. Luxembourg: Publications office of the European Union.

Maller, C., Townsend, M., St Leger, L., Henderson-Wilson, C., Pryor, A., Prosser, L., and Moore, M. (2009). Healthy parks, healthy people: the health benefits of contact with nature in a park context. The GWS Journal of Parks, Protected Areas \& Cultural Sites: 26(2): 51-83.

Mao, G., Lan, X., and Yan, J. (2012). Effects of short-term forest bathing on human health in a broad-leaved evergreen forest in Zhejiang Province, China. Biomedical and Environmental Sciences: 25(3): 317-324.

Mougiakou, E., and Photis, Y. N. (2014). Urban green space network evaluation and planning: optimizing accessibility based on connectivity and raster GIS analysis. European Journal of Geography: 5(4):19-46.

Mytton, O., Townsend, N., Rutter, H., and Foster, C. (2012). Green space and physical activity: An observational study using Health Survey for England data. Health \& Place: 18(5): 1034-1041.

Nowak, D., Hirabayashi, S., Doyle, M., McGovern, M., and Pasher, J. (2018). Air pollution remoual by urban forests in Canada and its effect on air quality and human health. Urban Forestry \& Urban Greening: 29: 40-48.

Pierce Colfer, C., Sheil, D., and Kishi, M. (2006). Forests and human health: assessing the evidence. Bogor, Indonesia: Center for International Forestry Research (CIFOR). CIFOR Occasional Paper; No. 45)

Public Institution of the Meduednica Nature Park. (2014). Sustainable Tourism Strategy and Action Plan. Zagreb: Public Institution of the Meduednica Nature Park.

Romagosa, F., Eagles, P., and Lemieux, C. (2015). From the inside out to the outside in: Exploring the role of parks and protected areas as providers of human health and well-being. Journal of Outdoor Recreation and Tourism: 10: 70-77.

Sandifer, P., Sutton-Grier, A., and Ward, B. (2015). Exploring connections among nature, biodiversity, ecosystem services, and human health and well-being: Opportunities to enhance health and biodiversity conservation. Ecosystem Services: 12: 1-15.

Sanesi, G., Gallis, C., and Kasperidus, H. (2010). Urban forests and their ecosystem services in relation to human health. In Forests, Trees and Human Health, eds. K. Nilsson, M. Sangster, C. Gallis, T. Hartig, S. de Vries, K. Seeland, et al., 25-42. Dodrecht: Springer.

Song, C., Joung, D., Ikei, H., Igarashi, M., Aga, M., Park, B. J., Miwa, M., Takagaki, M. and Miyazaki, Y. (2013). Physiological and psychological effects of walking on 
young males in urban parks in winter. Journal of Physiological Anthropology: 32(1): 1-7.

Van den Berg, A., Maas, J., Verheij, R., and Groenewegen, P. (2010). Green space as a buffer between stressful life events and health. Social Science \& Medicine: 70(8): 1203-1210. 